situated in slight brown shade; t. a. line broad, brown, angled twice inwardly, almost straight across wing; t. p. line brown, slightly dentate in upper portion, strongly outcurved just below costa, incurved somewhat opposite reniform, strongly incurved below same to inner margin, where a slight outward angle is formed; orbicular represented by a brown dot; reniform by two brown dots, situated at either extremity, placed vertically to each other ; from just beyond orbicular to t. p. line the median area is largely suffused with light brown; beyond the t. p. line is a narrow band of white, the remainder of the subterminal area washed with brown; subterminal line represented by a white, irregular, dentate band, beyond which the brown shading again obtains; fringes white, tinged with brown at extremities. Secondaries white.

Beneath primaries smoky-brown, whitish along inner margin; secondaries white, tinged with brown along costal margin and with traces of a brown postmedial line. Expanse, $28 \mathrm{~mm}$; 2 of $\mathrm{s}, 2$ s; Redington, Ariz.; Babaquivera Mts., Ariz. Types, Coll. Barnes.

The three brown dots representing respectively orbicular and reniform are quite characteristic. The of specimens are in very poor shape; but the $q$ is well preserved; the description has been drawn from the latter.

\title{
PREDACEOUS BUGS.
}

A very remarkable occurrence of predaceous bugs has taken place in Southwestern Ontario during the last few weeks. Correspondents in the counties of Dufferin, Norfolk, Oxford and Middlesex have sent in specimens of Perillus bioculatus Fabr, and of its variety, claudus Say. The latter form was described and figured in the Second Annual Report of the Entomological Society of Ontario, published in $187 \mathbf{r}$, under the name of Perillus circumcinctus. These bugs, both in the imago and nymphat forms, are destroying the Colorado Potato Beetles, both eggs, larve and mature beetles, to such an extent that in some fields it is reported that hardly any of the beelles are to be found, though the plants have not been sprayed. They are quite abundant also at the College in Guelph and other parts of the County of Wellington. The specimens have been kindly identified by Mr. E. P. Van Duzee, of Buffalo, N. Y. He expresses surprise at the species being found in this part of Ontario, as be considers it a southern form, and is rarely known to be found as far north as the State of Illinois. It is to be hoped that the insect may continue prevalent and keep the Colorado Potato Beetle in control.- [C. J. S. Bethune.

ERratu:I.-P. 286, line 7, for "poliachroa" read "poliochroa." 